\title{
Association between insulin therapy and quality of life in diabetes
}

\author{
Mariusz Dąbrowski', Wioleta Filip ${ }^{2}$, Beata $\mathrm{Huc}^{3}$ \\ ${ }^{1}$ Uniwersytet Rzeszowski; Wydział Medyczny, Poland \\ 2 Podkarpacki Szpital Wojewódzki im. Jana Pawła II w Krośnie, Poland \\ ${ }^{3}$ Szpital Miejski w Przemyślu, Poland \\ Dabrowski M, Filip W, Huc B. Association between insulin therapy and quality of life in diabetes. J Pre-Clin Clin Res. 2017; 11(1): 10-14. \\ doi: $10.26444 /$ jpccr/75145
}

\section{Abstract}

Introduction. Diabetes is associated with a lower quality of life (QoL). Insulin therapy is perceived as an additional factor affecting QoL. The objective of this study, using standardized tools, was to evaluate to what extent insulin treatment has an effect on QoL in diabetes.

Materials and method. 60 diabetic patients treated with insulin and 90 with oral drugs, all aged over 30, were included into the study. To assess the QoL of patients, SF-36 v.2 and WHOQOL-BREF questionnaires were used. In addition, demographic data were collected.

Results. Insulin treated patients had a significantly lower Mental Component Score in SF-36 v.2 questionnaire. No significant differences between the two groups were found in the components of physical domain of SF-36 v. 2 and in four domains of WHOQOL-BREF questionnaires. Insulin therapy was significantly associated with lower educational level. The strongest association with QoL in both questionnaires was found for professional activity and age.

Conclusions. The results of this study indicate the need for psychological support for patients with diabetes treated with insulin to improve their mental coping. Diabetic patients should also be advised to continue their professional activity for as long as possible due to its important role in maintaining QoL.

\section{Key words}

diabetes, insulin therapy, quality of life, SF-36 v.2 questionnaire, WHOQOL-BREF questionnaire

\section{INTRODUCTION}

During the last decades, the burden of diabetes has become one of the most important public health challenges worldwide. The number of people with diabetes is continuously increasing and its prevalence has even exceeded previous expectations $[1,2]$. Diabetes is associated not only with an increased risk of diabetes-related complications, but also with a higher prevalence of mood disorders, including depression, as well as with a reduced quality of life(QoL) [35]. QoL can be perceived as a multidimensional functioning in the surrounding world on the physical, mental, social and environmental areas [5]. The interest of the scientific world with the QoL assessment in diabetes dates back to late 1980s, and the number of publications considering QoL in the diabetic population has also increased remarkably in the last decades [3-10]. In the assessment of health-related QoL in diabetic subjects many questionnaires can be used, including generic [World Health Organization Quality of Life (WHOQOL), Short-Form 36 (SF-36), EuroQoL5-Dimension (EQ-5D),Beck Depression Inventory (BDI), Hospital Anxiety and Depression Scale (HADS), Well-Being Questionnaire (W-BQ)], and the diabetes-specific tools [Diabetes Quality of Life (DQOL), Audit of Diabetes-Dependent Qualityof Life (ADDQoL),Diabetes Treatment Satisfaction Questionnaire (DTSQ), and Problem Areas in Diabetes (PAID)]; obviously however, none of them is perfect [11-13]. In addition, it should be remembered that QoL is a very subjective phenomenon [6].

Address for correspondence: Mariusz Dąbrowski, Uniwersytet Rzeszowski; Wydział Medyczny, Poland

E-mail: mariusz.dabrowski58@gmail.com

Received: 17 December 2017; accepted: 9 March 2017
Many factors can affect a QoL in diabetic patients. Diabetes itself is perceived by patients as a challenge and considerable burden in their daily life. People suffering from diabetes should follow recommendations regarding diet and physical activity, they must remember to take antidiabetic medications, and also the self-monitoring of their blood glucose level, which requires pricking their own fingers. Thus, not surprisingly, diabetes is associated with a lower QoL [3-5]. It should also be kept in mind that type 2 diabetes is a progressive disease and in its course stepwise intensification of treatment over time is required, beginning usually from monotherapy, through 2-3 different oral drugs, up to insulin treatment in different regimens, with or without concomitant medications [14]. In everyday clinical practice the need to initiate insulin therapy is frequently perceived by insulin-naïve patients as a factor deeply disturbing their current lifestyle. They are afraid of injections, hypoglycaemia and weight gain, they are also worried about playing their social and family roles. Despite these concerns, most of the evidence indicate that initiation of insulin therapy usually does not deteriorate QoL; however, in different studies different questionnaires were used, and in many cases the results are not fully comparable due to different sensitivity and specificity of the questionnaires used $[6,15]$. Among the factors deteriorating health-related QoLin in diabetes, the presence of long-term diabetic complications and episodes of hypoglycemia can be pointed out [4, 15-17].

\section{OBJECTIVE}

The primary objective of this study was to evaluate to what extent insulin treatment influences the QoL in in diabetic patients by using standardized questionnaires: Medical 
Outcomes Study 36-Item Short-Form Health Survey (SF36 v.2) and World Health Organization Quality of Life Assessment Brief version (WHOQOL-BREF). A secondary objective was to analyze associations between other analyzed factors and QoL.

\section{MATERIALS AND METHOD}

150 patients with diabetes, aged $\geq 30$, treated in an outpatient setting in four centres: NZOZ Beta-Med in Rzeszow, Provincial Subcarpathian Hospital name of John Paul II in Krosno, NZOZ in Świerzów Polski, andSPZOZ in Jedlicze, were included into the study. All the centres are localized in the Podkarpackie (Subcarpathian) province in south-eastern Poland. Among the study population, 60 patients were treated with insulin, with or without additional oral medications, and 90 patients were treated with oral drugs or diet alone. All patients completed SF-36 v.2 and WHOQOL-BREF questionnaires. The first consisted of 36 questions in 2 scales: physical and mental, divided into eight domains addressing physical functioning and role, bodily pain, general health, vitality, social functioning, mental health and emotional role. The second has 26 questions addressing somatic, mental, social and environmental areas of functioning. In both questionnaires, the higher the score, the better the QoL. Both questionnaires are not diabetes-specific. Despite this limitation, they are considered as useful tools for assessment of the general health status and health-related quality of life among patients with diabetes [11]. Also demographic data: gender, age (4 groups: $30-39,40-49,50-59$ and $\geq 60$ years), place of residence (urban vs. rural), level of education (basic, vocational, secondary or higher school) and professional status (active vs. non-active) were obtained. Demographic characteristics of both groups are shown in Table 1.

Table 1. Characteristics of the studied population

\begin{tabular}{lccc}
\hline Parameter & \multicolumn{2}{c}{ Treatment } & \multirow{2}{*}{ P value } \\
\cline { 2 - 3 } & Oral/diet ( $n)$ & Insulin $(n)$ & \\
\hline Gender & 45 & 29 & 0.973 \\
female & 45 & 31 & \\
male & & & 0.168 \\
\hline Age (years) & 4 & 6 & \\
$30-39$ & 12 & 6 & \\
$40-49$ & 21 & 21 & \\
$50-59$ & 53 & 27 & 0.239 \\
$\geq 60$ & & & \\
\hline Place of residence & 35 & 30 & $\mathbf{0 . 0 3 8}$ \\
rural & 55 & 30 & \\
urban & & & \\
\hline Level of education & 9 & 10 & \\
basic & 20 & 19 & \\
vocational & 33 & 24 & \\
secondary & 28 & 7 & \\
higher & & & \\
\hline Occupational status & 53 & 29 & \\
active & 37 & 31 & \\
retired/unemployed & & & \\
\hline
\end{tabular}

Statistical analysis of the data was performed using SigmaPlot for Windows, version 12.5 (Systat Software Inc., San Jose, CA, USA). Numerical data were presented as numbers. The continuous data comparing 2 groups of patients were analyzed using an unpaired two-tailed Student's t-test or by a Mann-Whitney rank sum test where appropriate. The categorical data were analyzed using $\chi^{2}$ test. The associations between insulin treatment, demographic factors and quality of life were assessed using Spearman rank order correlation test. A P value of $<0.05$ was considered statistically significant.

The study was approved by Institutional Review Board at the University of Rzeszow and by all appropriate administrative bodies. Before completing the questionnaires, all study participants signed informed consent forms. Permission to use both questionnaires was obtained from the copyright holders.

\section{RESULTS}

SF-36 v.2 questionnaire. In the Student's t-test analysis, patients treated with insulin had a significantly lower mean score in the summary of mental components, compared to patients on oral drugs or diet alone, $\mathrm{p}=0.034$ (Fig. 1). Other results in the mental domain were also lower in the insulin group, but they did not reach statistical significance. No significant differences were found between the 2 groups in the components of the physical scale.

In the Spearman rank order correlation analysis, treatment with insulin was inversely associated with educational level $(\mathrm{R}=-0.220 ; \mathrm{P}=0.007)$. Patients with basic or vocational level of education were almost 2-fold more likely to be treated with insulin (OR [odds ratio] 1.968, [95\% CI [confidence interval] $1.005-3.854 ; \mathrm{P}=0.047$ ), compared to subjects with secondary or higher educational level. No other associations were found for insulin therapy. Among demographic factors, the strongest correlation with QoL was found for professional activity, predominantly among the physical components, but also with vitality and social functioning. Age was inversely correlated with the majority of physical components, and also with vitality. Male gender was associated with higher scores in physical domain, while it was inversely correlated with general health. Urban place of residence showed correlation only with physical role, while higher level of education was associated with higher scores in both physical and emotional roles (Tab. 2).

WHOQOL-BREF questionnaire. Student's t-test analysis did not revealed significant differences in any of the 4 domains of the WHOQOL-BREF questionnaire between insulin and oral/diet treated patients with diabetes (Fig. 2).

In the Spearman rank order correlation analysis, no associations between insulin therapy and quality of life were found. Among demographic factors, similar to SF-36 v.2 questionnaire, a strongest correlation with quality of life was revealed for professional activity. Also, age demonstrated significant association with all 4 domains of WHOQOLBREF questionnaire. Higher level of education showed strong association with a higher score in the environmental domain, and weaker association with the mental domain score. Also, urban place of residence demonstrated relationship with higher score in the environmental domain (Tab. 3). 


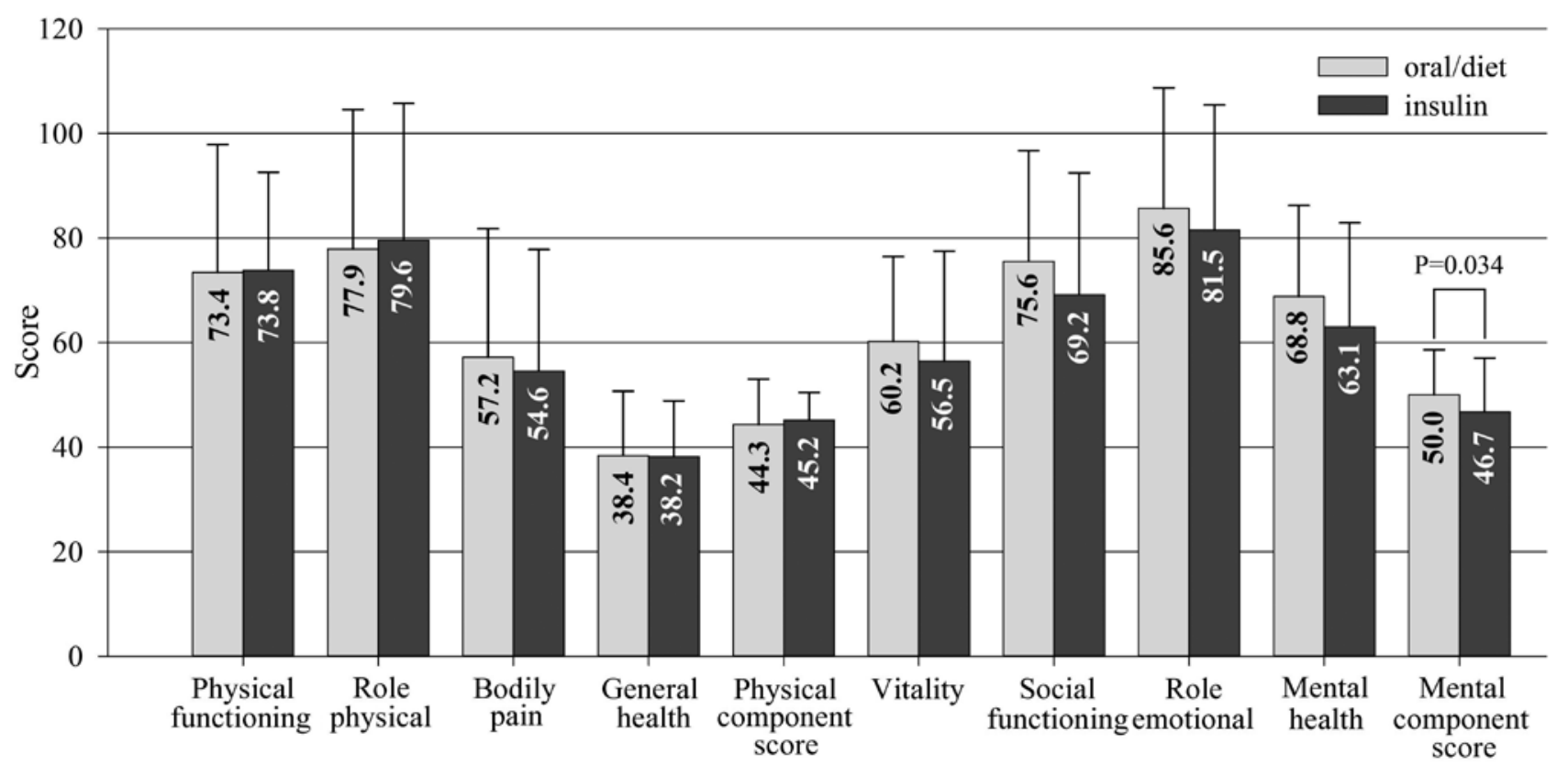

Figure 1. Scores achieved by oral and insulin treated patients in each component of physical and mental domains ofSF-36 v.2 questionnaire. Error bars - SD (standard deviation)

Table 2. Spearman correlation coefficient $R$ in relation to demographic and environmental factors in SF-36 v. 2 questionnaire

\begin{tabular}{|c|c|c|c|c|c|c|c|c|c|c|}
\hline Parameter & 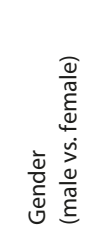 & $\frac{\frac{2}{2}}{\frac{\pi}{3}}$ & 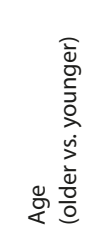 & $\frac{\frac{0}{3}}{\frac{0}{0}}$ & 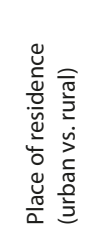 & $\frac{\frac{2}{2}}{\frac{\pi}{2}}$ & 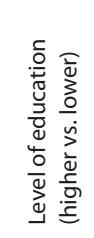 & $\frac{\frac{2}{2}}{\frac{\pi}{3}}$ & 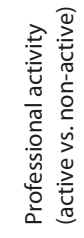 & $\frac{\frac{2}{3}}{\frac{10}{2}}$ \\
\hline Physical functioning & 0.142 & NS & -0.597 & $<0.001$ & 0.012 & NS & 0.077 & NS & 0.545 & $<0.001$ \\
\hline Role physical & 0.095 & NS & -0.120 & NS & 0.195 & 0.017 & 0.230 & 0.005 & 0.272 & $<0.001$ \\
\hline Bodily pain & 0.125 & NS & -0.300 & $<0.001$ & 0.054 & NS & 0.120 & NS & 0.274 & $<0.001$ \\
\hline General health & -0.203 & 0.013 & -0.088 & NS & -0.022 & NS & 0.016 & NS & 0.243 & 0.003 \\
\hline Physical Component Score & 0.059 & NS & -0.449 & $<0.001$ & 0.074 & NS & 0.155 & 0.058 & 0.526 & $<0.001$ \\
\hline Vitality & 0.051 & NS & -0.203 & 0.013 & -0.108 & NS & 0.062 & NS & 0.223 & 0.006 \\
\hline Social functioning & 0.242 & 0.003 & -0.092 & NS & -0.016 & NS & $<0.001$ & NS & 0.215 & 0.008 \\
\hline Role emotional & 0.173 & 0.035 & -0.035 & NS & 0.080 & NS & 0.236 & 0.004 & 0.137 & NS \\
\hline Mental health & 0.064 & NS & -0.088 & NS & -0.065 & NS & 0.069 & NS & -0.003 & NS \\
\hline Mental Component Score & 0.142 & NS & 0.046 & NS & -0.077 & NS & 0.084 & NS & -0.042 & NS \\
\hline
\end{tabular}

NS- non significant

Table 3. Spearman correlation coefficient $R$ in relation to demographic and environmental factors in WHOQOL-BREF questionnaire

\begin{tabular}{|c|c|c|c|c|c|c|c|c|c|c|}
\hline Domain & 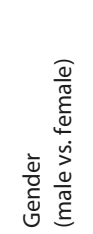 & $\frac{\frac{0}{2}}{\frac{2}{20}}$ & 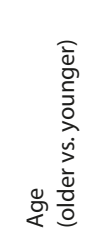 & $\frac{\frac{0}{3}}{\frac{\pi}{\pi}}$ & 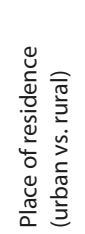 & $\frac{\frac{0}{2}}{\frac{2}{0}}$ & 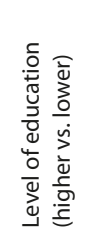 & $\frac{\frac{0}{2}}{\frac{\pi}{D}}$ & 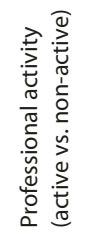 & $\frac{\frac{0}{2}}{\frac{2}{\pi}}$ \\
\hline Somatic & 0.012 & NS & -0.162 & 0.048 & 0.007 & NS & 0.158 & 0.053 & 0.231 & 0.005 \\
\hline Mental & 0.019 & NS & -0.258 & 0.001 & 0.032 & NS & 0.177 & 0.030 & 0.380 & $<0.001$ \\
\hline Social & -0.081 & NS & -0.172 & 0.035 & 0.037 & NS & 0.101 & NS & 0.228 & 0.005 \\
\hline Environmental & -0.011 & NS & -0.196 & 0.016 & 0.214 & 0.009 & 0.263 & 0.001 & 0.168 & 0.040 \\
\hline
\end{tabular}

NS-non-significant 


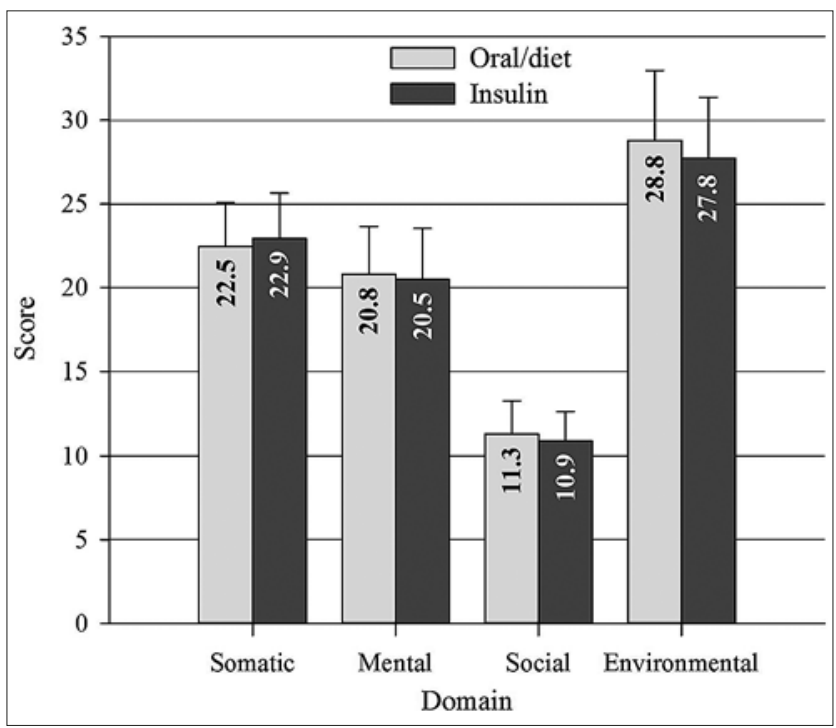

Figure 2. Scores achieved by oral and insulin treated patients in 4 domains of WHOQOL-BREF questionnaire. Error bars - SD

\section{DISCUSSION}

The diabetes therapy paradigm has changed in the last decade. Current treatment goals in diabetes are not limited solely to metabolic control and prevention of acute and chronic complications, but also include preservation of good QoL[3]. Patients with diabetes are known to have a worse QoL compared with non-diabetic subjects [3-8]. Among factors related to decreased QoL in diabetes, the presence of diabetic complications, especially advanced, and episodes of hypoglycaemia are considered to be the most important $[14,15]$. Insulin therapy is also considered as a factor having strong effect on patients' functioning. Its impact is divergent. On the one hand, insulin therapy leads to amelioration of the symptoms of hyperglycaemia and to improvement of metabolic control (which, in turn, is related to lower risk of diabetic complications), while, on the other hand, it is associated with an elevated risk of hypoglycaemia, frequently leading to weight gain, and is perceived by patients as a factor limiting their social functioning. Moreover, patients also feel stigmatized by insulin and have a sense of loss of control over diabetes [6].

There are several studies evaluating the effect of insulin therapy on QoL in diabetes. In a study performed in 200 Polish patients, comparing directly QoL between patients treated with insulin and patients on oral drugs, similar to the presented results, no significant differences in the WHOQOLBREF questionnaire were found. No other standardized questionnaires were used in this study [18]. In another study involving 37 patients with type 2 diabetes, treatment with insulin was associated with worse QoL. In this study, SF36 v.2 questionnaire was used; however, no exact scores were provided [19]. Initiation of insulin therapy is usually associated with improvement or to have neutral impact on QoL. In a large observational study in India, initiation of insulin analogue-based treatment in 44,872 insulin naïve patients was associated with significant improvement of QoL. Also, patients switched from human insulins to insulin analogues reported improvement in QoL [20]. Similar results were obtained in a Chinese observational study evaluating the effect of initiation of biphasic insulin aspart 30 in 6,612 insulin naïve patients, or switching to this insulin analogue in 1,966 already insulin-treated subjects [21]. In a Dutch prospective cohort study, initiation of insulin glargine in both insulin-naïve as well as in insulin-treated patients with type 2 diabetes, resulted in improvement in QoL [22]. However, in a prospective, multicentre, randomized, open label, crossover study conducted in Holland, no differences were found between patients initiating insulin glargine and insulin NPH regarding QoL [23]. Initiation of insulin therapy in connection with structured education demonstrated a significant improvement in metabolic control, which was associated with positive changes in several domains of QoL [24].

In the current study, patients already treated with insulin were involved. This therapy appeared not to be associated negatively with physical functioning, while mental status was depressed by insulin therapy. This indicates a strong need for psychological care in diabetic patients, and underlines the role of education which may be helpful for the coping of patients in this area.

Several demographic factors also appeared to have an effect on QoL in diabetes. In a French study, demographic factors such as age, gender, educational level, income and type of occupational activity were associated with QoL. Lower age, male gender, higher income and higher educational level were associated with better QoL, both in physical and in mental component score in SF-12 questionnaire. Regarding professional activity, the highest QoL was found in patients working in executive and superior intellectual professions [25]. In a mentioned earlier Polish study, higher income, lower age and male gender were associated with better QoL. Interestingly, in this study, higher educational level was associated with worse QoL [19]. In the presented study, continued professional activity (which can be associated also with higher income), as well as lower age, were associated with better QoL, predominantly in the components of physical domain in SF-36 v.2 questionnaire, and with all components of WHOQOL-BREF questionnaire. Male gender, similar to above-cited studies, was associated with higher scores in social functioning and playing roles in emotional domain, while men had lower scores in the general health domain. Similar to a French study, higher educational level positively correlated with playing physical and emotional roles in SF36 v.2 questionnaire, and with mental and environmental domains in WHOQOL-BREF questionnaire. In the latter questionnaire, a borderline trend towards better functioning in somatic domain was also found. Interestingly, patients with lower educational level were more frequently treated with insulin. This phenomenon can be explained by better ability to cope with the burden of the disease, and possibly a greater awareness of risks associated with diabetes observed in better educated patients. Place of residence was not analyzed in earlier mentioned studies. In the current study, rural place of residence appeared to affect playing physical roles in SF-36 v.2 questionnaire, and was also associated with lower scores in the environmental domain of WHOQOLBREF questionnaire.

The limitations of this study include lack of data regarding diabetes duration and its metabolic control. Also, no information regarding diabetes complications are provided. However, the study also has several strengths. The first is a diverse population, large enough to find 
significant associations between diabetes, its treatment, demographic factors and QoL. The second strength is the use of standardized questionnaires, which allow comparison of the results with the results of other studies conducted with the use of the same questionnaires. The results of this study can, therefore, be considered validated and reliable.

\section{CONCLUSIONS}

Diabetes itself is associated with a worse QoL compared to non-diabetic subjects. In this study, insulin treatment appeared to be a factor affecting mental subscale of healthrelated QoL. Thus, the results of our study, supported by existing evidence, indicate that:

- There is a need for psychological and educational support for insulin-treated diabetic patients to maintain or even improve their QoL, predominantly in the mental domain.

- This support can be more frequently expected among women than among men

- Diabetic patients should be also be advised to continue their professional activity for as long as possible due to its important role in maintaining quality of life.

- Earlier insulin treatment may be required in patients with lower educational level; thus, in these patients, earlier and more intensive educational efforts focused on coping with diabetes-related problems are required.

- QoL assessment using standardized tools should become a part of a routine diabetes care.

\section{Conflict of interest}

The authors declare no conflict of interest in the area covered by this study.

\section{Statement on Human and Animal Rights}

All procedures were followed in accordance with the ethical standards of the responsible committee on human experimentation (institutional and national) and with the Helsinki Declaration of 1975, as revised in 2008.

\section{REFERENCES}

1.International Diabetes Federation. IDF Diabetes Atlas. Sixth edition. 2014 Update. Available at: http://www.idf.org/diabetesatlas/update-2014. Accessed 13th August 2015.

2.Wild S, Roglic G, Green A, Sicree R, King H. Global prevalence of diabetes: estimates for the year 2000 and projections for 2030. Diabetes Care. 2004; 27(5): 1047-1053.

3.Schram MT, Baan CA, Pouwer F. Depression and quality of life in patients with diabetes: a systematic review from the European depression in diabetes (EDID) research consortium. Curr Diabetes Rev. 2009; 5(2): 112-119.

4. Norris SL, McNally TK, Zhang X et al. Published norms underestimate the health-related quality of life among persons with type 2 diabetes. J ClinEpidemiol. 2011; 64(4): 358-365.

5. Rubin RR, Peyrot M. Quality of life and diabetes. Diabetes Metab Res Rev. 1999; 15: 205-218.

6. Pouwer F, Hermanns N. Insulin therapy and quality of life. A review. Diabetes Metab Res Rev. 2009; 25(Suppl 1): S4-S10.
7. de Grauw WJ, van de Lisdonk EH, Behr RR, van Gerven WHEM, van den Hoogen HJM, van Weel C. The impact of type 2 diabetes mellitus on daily functioning. Fam Pract. 1999; 16: 133-139.

8. Hörnquist JO, Wikby A, Stenström U, Andersson PO, Akerlind I. Type II diabetes and quality of life: a review of the literature. Pharmacoeconomics. 1995; 8(Suppl 1): 12-16.

9. Kemmer FW, Berger M. Therapy and better quality of life: the dichotomous role of exercise in diabetes mellitus. Diabetes Metab Rev. 1986; 2(1-2): 53-68.

10. Eiser C, Tooke JE. Quality of life in type II diabetes: evaluation and applications. Pharmacoeconomics. 1995; 8(Suppl 1): 17-22.

11. Speight J, Reaney MD, Barnard KD. Not all roads lead to Rome - a review of quality of life measurement in adults with diabetes. Diabet Med. 2009; 26(4): 315-327.

12. Dudzińska M, Tarach JS, Nowakowski A. Pomiar jakości życia zależnej od zdrowia w cukrzycy (Measurement of health-relatedquality of life in diabetesmellitus). Diabet Prakt. 2011; 12(2): 56-64 (in Polish).

13. Levterova BA, Dimitrova DD, Levterov GE, Dragova EA. Instruments for disease-specific quality-of-life measurement in patients with type 2 diabetes mellitus - a systematic review. Folia Med (Plovdiv) 2013; 55(1): 83-92.

14. Inzucchi SE, Bergenstal RM, Buse JB, et al. Management of hyperglycemia in type 2 diabetes, 2015: A patient-centered approach. Update to a Position Statement of the American Diabetes Association and the European Association for the Study of Diabetes. Diabetes Care 2015; 38: $140-149$.

15. UKPDS Group. Quality of life in type 2 diabetic patients is affected by complications but not by intensive policies to improve blood glucose or blood pressure control (UKPDS 37). Diabetes Care 1999; 22: 1125-1136.

16. Quah JH, Luo N, Ng WY, How CH, Tay EG. Health-related quality of life is associated with diabetic complications, but not with short-term diabetic control in primary care. Ann Acad Med Singapore. 2011; 40(6): 276-286.

17. Barendse S, Singh H, Frier BM, Speight J. The impact of hypoglycaemia on quality of life and related patient-reported outcomes in Type 2 diabetes: a narrative review. Diabet Med. 2012; 29(3): 293-302.

18. Fal AM, Jankowska B, Uchmanowicz I, Sen M, Panaszek B, Polanski J. Type 2 diabetes quality of life patients treated with insulin and oral hypoglycemic medication. Acta Diabetol. 2011; 48(3): 237-242.

19. Pufal J, Gierach M, Pufal M, Bronisz A, Kiełbasa L, Junik R. Wpływ czynników społeczno-demograficznych i klinicznych na jakość życia chorych na cukrzycę typu 2 (The influence of socio-demographic and clinicalfactors on qualityof life of patients with type 2 diabetes). Diabetologia Dosw Klin 2004; 4(2): 137-143 (in Polish).

20. Shah S, Zilov A, Malek R, Soewondo P, Bech O, Litwak L. Improvements in quality of life associated with insulin analogue therapies in people with type 2 diabetes: results from the Alchieve observational study. Diabetes Res Clin Pract. 2011; 94(3): 364-370.

21. Yang W, Zhuang X, Li Y, Wang Q, Bian R, Shen J, Hammerby E, Yang L. Improvements in quality of life associated with biphasic insulin aspart 30 in type 2 diabetes patients in China: results from the Alchieve observational study. Health Qual Life Outcomes. 2014;12: 137. doi: 10.1186/s12955-014-0137-9.

22. Hajos TR, Pouwer F, de Grooth R, et al.Initiation of insulin glargine in patients with Type 2 diabetes in suboptimal glycaemic control positively impacts health-related quality of life. A prospective cohort study in primary care. Diabet Med. 2011; 28(9): 1096-1102.

23. Hermanns N, Kulzer B, Kohlmann T, et al. Treatment satisfaction and quality-of-life between type 2 diabetes patients initiating long- vs. intermediate-acting basal insulin therapy in combination with oral hypoglycemic agents - a randomized, prospective, crossover, open clinical trial. Health Qual Life Outcomes. 2015 Jun 9; 13: 77. doi: 10.1186/ s12955-015-0279-4.

24. Braun A, Sämann A, Kubiak T, et al. Effects of metabolic control, patient education and initiation of insulin therapy on the quality of life of patients with type 2 diabetes mellitus. Patient Educ Couns. 2008; 73(1): 50-59.

25. Bourdel-Marchasson I, Druet C, Helmer C, et al. Correlates of healthrelated quality of life in French people with type 2 diabetes. Diabetes Res Clin Pract. 2013; 101(2): 226-235. 